\title{
Stentless mitral valves
}

Robert W. M. Frater, MD

See related article on page 986 .

From the Department of Cardiothoracic Surgery, Montefiore Medical Center, Bronx, NY. Received for publication September 6, 2006; accepted for publication September 20, 2006.

Address for reprints: Robert W. M. Frater, MD, Montefiore Medical Center, Department of Cardiothoracic Surgery, 1575 Blondell Avenue, Suite 125, Bronx, NY 10467 (E-mail: Rwmfglycar@aol.com).

J Thorac Cardiovasc Surg 2007;133:861-4

0022-5223/\$32.00

Copyright $\odot 2007$ by The American Association for Thoracic Surgery

doi:10.1016/j.jtcvs.2006.09.119

$\mathrm{T}$ The natural mitral valve is a complex and finely tuned structure, very well suited to its purpose. It has the unusual feature of having fingerprint anatomic variation from heart to heart and yet the correct essentials for optimal function in each heart. Among the many features is that the mural annulus expands for flow and narrows for closure and that the multiscalloped posterior leaflet makes expansion and contraction possible. In diastole the scallops are separate; in systole they are compressed into a shelf.

The chordae are of two types, despite their extreme variability: one to align the free edges and one to bear the load of the closed valve and transmit that load to the ventricular wall and aid in systolic ejection.

The Encyclopedia Britannica of 1895 described all of the devices for allowing fluid to travel in one direction and preventing it from traveling in an opposite direction that had been developed by the engineers of the Industrial Revolution. The principle of every type of mechanical valve that we have adapted for use in the heart in the last 45 years is to be found there. There are even flap valves made of leather. There is no valve with a dynamic orifice that enlarges for flow and narrows for closure. There is no valve with downstream support divided between one set of chordae to align the leaflet edges and one set to support the load of the closed valve. There is no valve that resembles the natural mitral valve.

Surgeons started trying to design artificial mitral valves in the late 1950s. Most sought mechanical solutions. If we define success as replacement of the mitral valve followed by discharge of a live patient from the hospital, then the first success followed the implantation of a stentless mitral valve made by Nina Braunwald and inserted by Glen Morrow in 1960. It was a bileaflet valve of molded polyurethane with its free edges supported by polyester chordae brought together into two groups and secured outside the ventricular wall. It resembled a rheumatic valve after a good commissurotomy. Ever since then the dream of a stentless chordally supported mitral valve has persisted.

Stentless mitral valves all have a more or less bileaflet structure with a pliable sewing ring and a distal connection between the leaflet edges and the left ventricular wall. They can be classified into three main types:

1. Harvested natural mitral valves that may be allograft or xenograft.

2. Tubular sleeves of biological tissue that are directly attached at each side to the left and right papillary muscles.

3. More or less bileaflet valves with synthetic sutures or extensions of the leaflet edges that are attached to papillary muscles to maintain annular-papillary connection.

I have excluded for brevity's sake autograft or allograft harvested pulmonary or aortic valves mounted upside down in a tube graft. Although these valves have been called "stentless," the tube controls their motion very much the way a 3-pronged stent does.

\section{Harvested Natural Mitral Valves}

It is fair to say that there has never been widespread use of these devices despite research that began in the late 1960s. The major reason for this has been the extreme anatomic irregularity of papillary muscles and their chordal origins. This irregularity applies, naturally, to both donor and host, so that there needs to be selection of a donor and, to a lesser extent, a host with properly matching anatomy. Homograft insertion was greatly helped by the technique of side-by-side papillary attachment 
combined with the routine use of an annuloplasty ring. Acar ${ }^{1}$ developed these improvements, but as the leading exponent of homograft mitral valve replacement he acknowledges that its use is still in the research stage.

In the case of xenografts, attempts were made to simplify the fixing of the valve to the papillary muscle by suturing the left and right donor papillary/chordal complexes to a pericardial flap ${ }^{2}$ or enclosing them in a tube, ${ }^{3}$ but in neither case was the expected benefit achieved. Both homografts (subject to strength deterioration between harvesting and use) and aldehyde-fixed xenografts have had early chordal rupture and leaflet tears in clinical use.

If we imagine the embryonic chordae developing exactly the right thickness, strength, and length for the function they are performing in the growing heart, it can be understood that a tilting of the attachment could subject chordae to stresses greater than those they grew to tolerate. Apart from the one xenograft porcine mitral valve that did reach clinical use for a limited time, ${ }^{2}$ there have been several versions that did not get past the animal testing stage.

\section{Tubular Sleeves of Biological Tissue}

Tubular sleeves have been made of untreated and aldehydetanned autogenous pericardium, as well as aldehyde-tanned xenograft pericardium. ${ }^{4-6}$ In most, the anterior part of the tube is deeper than the posterior so the closure line has a curve that is somewhat parallel to the mural annulus. Ventricular attachment has generally been to the inside of each papillary muscle at the commissures between the deeper anterior leaflet and the shallower posterior leaflet. At least one design has extra layers of material for reinforcement of the attachment. In my experience of copying and testing valves of this type in vitro and in vivo, and in my observations of the designs of others implanted in animals and humans, I have observed that the pericardium representing the posterior leaflet commonly develops folds in closure. ${ }^{5}$ These folds give the appearance of multiple scallops. With a contractile annulus and a supple sewing "ring," nature reproduces in closure the natural scalloped form of the native mitral valve. Deac and colleagues, ${ }^{6}$ who worked long and hard to promote the concept of stentless mitral valves, published acceptable results of a small series of homemade versions of this category of valve, but despite much effort at commercialization this has not been achieved.

\section{Bileaflet Valves With Chordal Support}

Van der Spuy ${ }^{7}$ described such a valve made from fascia lata and polyester chordae. The valve described in this issue of the Journal by Jose Navier and coauthors ${ }^{8}$ and the Quattro valve $^{9}$ are two valves with this form in which the chordal support is provided by extensions of the leaflet pericardium. Both have resemblances to the natural valve, having a large anterior leaflet meeting a shallow posterior leaflet. The former has a shelf-like posterior leaflet that resembles the shelf-like form of the posterior leaflet of the natural valve after the scallops have been compressed together by normal systolic annular contraction or fused at their commissures by the rheumatic process. In the Quattro valve there are three distinct posterior scallops connected at the commissures. The left and right chordal extensions of the leaflets in both these designs are sutured to the bulky anterior part of each papillary muscle. In closure the three posterior scallops of the Quattro valve meet along their sides, producing an appearance similar to the closed natural valve. Both these valves are constructed from aldehyde-tanned xenograft pericardium. The Quattro valve has an anticalcification posttanning treatment. There have been multiple publications on the Quattro valve describing various aspects of its performance, the most recent being a report of experience between 1996 and 2004 from the three sites where the majority of the trial implants were performed. ${ }^{9}$

\section{Partial Replacement}

Navia and colleagues ${ }^{8}$ included the concept of partial replacement. This was tried extensively in the early days of mitral valve repair, using pericardium for selective leaflet and chordal replacement. ${ }^{10}$

The method described by Navia and colleagues ${ }^{8}$ involves incising the continuous sleeve of natural leaflet tissue circumferentially so it is no longer connected with the annulus. Continuity is restored by suturing the bileaflet valve without its chordal parts to the proximal and distal margins of the cut leaflet tissue. There was once a rheumatic pathology in which the leaflets shrunk but both leaflet tissue and chordae retained some flexibility. One remedy was to restore the lengths of the shortened leaflets with separate gussets of pericardium. ${ }^{11}$ Another remedy, described by Bailey and Hirose $^{12}$ and Edwards and Holdefer, ${ }^{13}$ using untreated autogenous pericardium, was essentially the same as Navia and colleagues' method. ${ }^{8}$ Navia and colleagues' use of part of this prosthesis will certainly work for the pathology described, but the indication for it will be uncommon.

The questions that inevitably arise from all this work are (1) What has been learned? and (2) Where are we going?

\section{What Has Been Learned? Implantability}

The need to attach the valve to the papillary muscles unquestionably makes these valves more difficult to insert. In the Quattro trial a majority of the surgeons who were asked and agreed to participate seemed to manage the insertion well, but they were experts at exposing the mitral valve. I suspect the sleeve-type valves may be the easiest.

\section{Hemodynamics}

It is tempting to assume that, like stentless aortic valves, stentless mitral valves have as their raison d'etre better 
hemodynamics when annuli are small. This is not so: In adults it is rare for the annulus to be so small as to force the insertion of a mitral valve too small to produce the immediate improvement in hemodynamics and symptoms that is the universal response after mitral valve replacement. Even the possibility that resolution of pulmonary hypertension may depend on a specific mitral effective orifice index is proving difficult to establish. There is a simple relationship between the pressure needed to drive a normal stroke volume across the orifice of an aortic valve that determines whether the resulting decrease in left ventricular pressure will allow hypertrophy to resolve. The mechanisms that cause pulmonary hypertension and allow it to resolve are far more complex, and in some patients, despite excellent relief of mitral obstruction, pulmonary hypertension persists for as long as 1 year.

In general, stentless valves have hemodynamic performance that is equivalent to the general run of current mitral prostheses. Of the three categories in our classification the sleeve valves have larger orifice areas for a given mounting size. This may be related to the absence of subvalvular apparatus in the flow path. Stentless valves are susceptible to oversizing, which results in crowding of folded leaflet tissue in the orifice. Their flexible sewing rings also make them susceptible to distortion, which can result in insufficiency. In all of these valves the sewing rings do not and cannot expand for diastolic flow.

\section{Durability}

Durability of a tissue valve results from resistance to structural failure in response to repetitive cycling and resistance to calcification over time, particularly in young patients. Pannus formation is generally regarded as nonstructural failure, especially when evaluating mechanical valves; in stentless valves it can have the effect of fundamentally interfering with function.

All stentless valves that have undergone long-term animal or human trials have had structural failure in the form of tears. These have occurred early in harvested valves and after some years in the others. In the case of the Quattro, the design called for a partial imitation of nature with selection of pericardium with the collagen fiber direction running between the annulus and the papillary attachment in the leaflet/chordal flap combinations. In multiple wear tests, complete resistance to tears was demonstrated. However, in the clinical trial 3 cases developed tears after 4 to 5 years, necessitating reoperation. Examination of the removed valves indicated that the collagen fibers ran in a transverse direction parallel with the tears: The system for identifying fiber direction was not sufficiently robust and had to be changed.

The pericardium used in the construction of the Quattro valve has an anticalcification treatment. It was hoped that durability would be enhanced by the absence of stent- produced stresses, which in 3 leaflet bioprostheses are related to the location of both calcium deposits and tears. The Quattro trial was unique in the deliberate choice of young patients to test the effectiveness of the treatment. The trial showed a much later onset of calcification in patients aged less than 40 years than was seen in stented, untreated bioprostheses in the past, but from 6.5 years on some calcification has been seen. Pannus has also occurred, and as the fibrous tissue starts growing onto the leaflets it affects flexibility, and therefore function, immediately. In all cases in which valves have been removed, the healing to the annulus has been sufficiently fibrous to suggest that free annular contraction may be limited.

\section{Ventricular Function}

Ventricular function was well preserved in the Quattro cases. The attachment of free edge chordal support to the part of the papillary muscles normally supporting the anterior leaflet achieved this without the need for separate second-order chordae. The automatic maintenance of annular-papillary continuity is the feature common to all stentless mitral valves.

\section{What Has Been Achieved and Where Are We Going?}

There were two dreams in the beginning. The first was to recreate the natural valve. It is clear that apart from the fact that the artificial valves we have made are not alive and generally are a form of leather, the best we achieve resembles a valve with mild rheumatic disease and a fixed annulus.

The second dream was to create a durable biological valve for the special needs of the developing world. It is no coincidence that virtually all the innovators have had personal experience of those needs. We have made some progress, but to prove a substantial improvement will take longer follow-up of young patients. It will not be sufficient to aim at the statutory 800 patient-years for a single-site device. This is commonly done with a large number of patients followed for a short time. It can be done with 400 patients followed for 2 years. Despite the expense of this, the fact that it can be done relatively quickly is vital to stockholder companies beholden to the need to satisfy Wall Street analysts. But 800 patient-years garnered in this way is totally useless to determine resistance to calcification; for that, a follow-up of 80 young patients, each followed for at least 10 years, is far more likely to provide the answer. To wait 10 years to be able to sell a product at low-profit margins is not attractive to investors.

North America and Europe, with a pocket in Japan, have been the markets to which major valve companies are aimed. With the growth of large middle classes in China and India, valves developed in North America and Europe are increasingly being sold there at the relatively high prices that make it possible to make a profit on devices developed to the standards of the Association for the Advancement of Medical Instrumentation, Food and Drug Administration, 
and International Organization for Standardization. The rural poor in the developing world continue to contract rheumatic heart disease and to need a durable inexpensive device that does not require anticoagulation.

For the dreamers, the road ahead is very hard. The paradigm of valve development in the developed world does not work for them. It is perhaps a moot point whether rheumatic fever will be eradicated before a cheap and durable device without requirement for anticoagulation is finally proven. I suspect that there will still be a reservoir of patients needing the latter before the former is achieved.

\section{References}

1. Acar C. The mitral homograft-is it worthwhile? J Thorac Cardiovasc Surg. 2003;125:84-5.

2. Vrandecic MP, Gontijo B, Fantini FA, et al. In: Heterologous mitral valve transplant: the first 50 patients. J Cardiovasc Surg. 1959;9:6574.

3. Timek LA, Lai DT, Tibayan FA, et al. Hemodynamic performance of an unstented xenograft mitral valve substitute. $J$ Thorac Cardiovasc Surg. 2002;124:541-52.
4. Ovil Y. Replacement of cardiac valves in heart surgery. US patent 4 790844 December 13, 1988.

5. Mickleborough L, Ovil Y, Wilson GJ, et al. A simplified concept for a bileaflet atrioventricular valve that maintains annular-papillary muscle continuity. J Card Surg. 1989;4:58-68.

6. Deac RFP, Simionescu D, Deac D. New evolution in mitral physiology and surgery: mitral stentless pericardial valve. Ann Thorac Surg. 1995;60:S433-8.

7. Van der Spuy JC. Considerations in the prosthetic construction of a completely anatomical whole mitral valve from autogenous tissues. S Afr Med J. 1964:771-5.

8. Navia JL, Doi K, Atik FA, et al. Acute evaluation of in vivo performance of new stentless mitral valves. J Thorac Cardiovasc Surg. 2007;133:986-94.

9. Frater RWM, Sussman M, Middlemost S, et al. Quattro valve trial at midterm: Dec 1996-Nov 2004. J Heart Valve Dis. 2006;15:230-7.

10. Frater RWM, Berghuis J, Brown AL, Ellis FH Jr. Autogenous pericardium for posterior mitral leaflet replacement. Surgery. 1964;84: 260-8.

11. Frater RWM. Anatomical rules for the plastic repair of the mitral valve. Thorax. 1964;19:458-63.

12. Bailey CP, Hirose T. Maximal reconstitution of the stenotic mitral valve by neostrophingic mobilization (rehinging of the septal leaflet). J Thorac Surg. 1958;35:559-83.

13. Edwards WS, Holdefer WF. Partial and complete reconstruction of the mitral valve with pericardium. In: Brewer LA III, ed. Prosthetic Heart Valves. Springfield, IL: Charles C. Thomas; 1969:820-8.

\section{Notice of Correction}

\section{Results of ACOSOG Z0050 trial: The utility of FDG-PET in staging potentially operable non-small cell lung cancer}

To the Editor:

As the result of re-review of data from the American College of Surgeons Oncology Group Z0050 trial $^{1}$ in preparation for an analysis of the use of brain FDG-PET in operable lung cancer, ${ }^{2}$ some corrections to the originally published data are reported. As published, FDG-PET correctly identified M1 disease in 15 of 287 patients (5.2\%). It was reported that in 19 of 287 evaluable patients (6.6\%) possible M1 disease was ruled out with confirmatory procedures (additional imaging or biopsy). Re-review of the PET reports in this group revealed that two cases ( 1 brain, 1 bone) were erroneously included by only blinded PET review and 4 cases ( 3 brain, 1 esophagus) were not suspicious per site PET report re-read. It was also reported that M1 disease was indicated by PET in 8 additional patients that the surgeon chose to overrule. Re-review shows that two cases (1 brain, 1 esophagus) were erroneously included.

These corrections do not alter the conclusions of the ACOSOG Z0050 trial. However, the reported percentage of patients with PET findings indicative of M1 disease subsequently proven not to be metastatic decreases from $6.6 \%$ to $4.5 \%$.

\section{References}

1. Reed CE, Harpole DH, Posther KE, Woolson SL, Downey RJ, Meyers BR, et al. Results of the American College of Surgeons Oncology Group Z0050 trial: The utility of positron emission tomography in staging potentially operable non-small cell lung cancer. J Thorac Cardiovasc Surg. 2003;126: 1943-51.

2. Posther KE, McCall LM, Harpole DH, Reed CE, Rusch VW, Siegel BA. Yield of brain FDG-PET in evaluating patients with potentially operable non-small cell lung cancer. $J$ Nuc Med. 2006; 47:1607-11. 